\title{
Extreme wind climatology of winter storms in Germany
}

\author{
Thomas Hofherr ${ }^{1,2, *}$, Michael Kunz ${ }^{2}$ \\ ${ }^{1}$ Geo Risks Research, Münchener Rückversicherungs-Gesellschaft, 80802 Munich, Germany \\ ${ }^{2}$ Institute for Meteorology and Climate Research (IMK), Karlsruhe Institute of Technology (KIT), Kaiserstrasse 12, \\ 76128 Karlsruhe, Germany
}

\begin{abstract}
A method for the assessment of the local hazard caused by large-scale winter storms is described in detail and applied to all of Germany. Spatially highly resolved wind fields of severe storm events in the climatological period from 1971 to 2000 are modeled by a statistical-dynamical downscaling approach with the Karlsruhe Atmospheric Mesoscale Model KAMM, using both ERA40 re-analysis and observation data. Hazard curves, including quantification of the uncertainties, are determined for all grid points with a distance of $1 \mathrm{~km}$ from the modeled wind fields by applying extreme value statistics. The hazard maps reveal critical regions with potentially extreme wind speeds depending on exposure, terrain height and land use. For an exceedance probability of $0.05 \mathrm{yr}^{-1}$ that equals a return period of $20 \mathrm{yr}$, the maximum gusts range between $26 \mathrm{~m} \mathrm{~s}^{-1}$ in deep valleys and $>45 \mathrm{~m} \mathrm{~s}^{-1}$ near the coast as well as over the crests of the low mountain ranges. Particularly saddles, edges, flanks and summits feature a higher hazard for extreme wind speeds. Comparisons of model data and observations confirm the applicability and the high precision of the method.
\end{abstract}

KEY WORDS: Winter storm • Extreme winds · Storm climatology - Hazard assessment . Extreme value statistics $\cdot$ Mesoscale modelling

Resale or republication not permitted without written consent of the publisher

\section{INTRODUCTION}

Severe winter storms that usually develop and amplify over the northern Atlantic are characteristic features of European climate. Associated extreme wind speeds give rise to severe damage or even loss of life. In Central Europe, winter storms are responsible for $56 \%$ of the total economic and $64 \%$ of the insured loss caused by natural hazards (Munich Re 2007). Single extreme events with a low probability of occurrence as, for example, the storms Lothar on 26 December 1999 or Kyrill on 18 January 2007 entail a damage potential in excess of $€ 10$ billion. Accurate assessment of extreme near-surface wind speeds and their probabilities, therefore, is a fundamental prerequisite for engineering, forestry and risk management. Whereas for risk assessment it is often sufficient to assess storm climatology by a rough approach, it is of prime importance in local planning to capture it on a local or regional scale.
The wind close to the earth's surface is strongly influenced by a broad range of atmospheric disturbances at different scales (Kalthoff et al. 2003). At a large scale, the wind field is primarily determined by the intensity and frequency of extratropical cyclones, both of which increase from south to north in Central Europe. On a local scale, the wind field is strongly modified by orographically induced deflections of the large-scale flow (Smith 1979, 1985), by friction flow depending on land use characteristics (Wieringa 1993) and by the structure of the boundary layer (Kalthoff et al. 2003). Consequently, the local wind climate may largely differ from that on the synoptic scale, especially over complex terrain (Whiteman \& Doran 1993, Adrian \& Fiedler 1995). Short-term fluctuations referred to as wind gusts are decisive for the destructive impacts of storms. They primarily depend on the terrain's roughness length. Generally, the highest wind speeds occur over and downstream of mountain tops and ridges, 
whereas the lowest wind speeds are observed in deeply incised valleys (Lux 2007). Reviews of the boundarylayer meteorology of wind flow over complex terrain are provided, for example, by Carruthers \& Hunt (1990), Meroney (1990) and Belcher \& Hunt (1998).

Comprehensive assessment of the local storm climate requires consideration of wind data at a high spatial resolution to capture the most important localscale amplification effects. Furthermore, sufficient longterm series are necessary to account for the most severe storms that occur very rarely. By applying extreme value statistics to a sample of extremes, wind speed is related to probability, usually expressed by its inverse, the return period. This relation is referred to as storm hazard.

In general, it is problematic to derive storm climatology directly from ground-based observations, since these often lack temporal homogeneity. Besides, the density of networks is usually too coarse to resolve important terrain variations. Most of the studies that are based on station data aim at estimating local (Dukes \& Palutikof 1995) or area-wide statistical return levels (Kasperski 2002). In Germany, the German building code uses wind speed characteristics such as gust wind speed, mean wind speed and wind direction for the adaptation of buildings to the present wind hazard, but in a very coarse spatial resolution (DIN 2005).

To overcome the limitations of surface observations, numerical mesoscale models were applied in the past to reproduce reliable surface wind fields on a regional scale. Useful sources for the study of historic storm events are the re-analysis project carried out by the National Center for Environmental Prediction and National Center for Atmospheric Research (NCEPNCAR; Kalnay et al. 1996) and the ERA-40 re-analysis project (Simmons \& Gibson 2000) of the European Centre for Medium-Range Weather Forecast (ECMWF). Several studies demonstrated that re-analysis data sets provide a powerful basis for analysing characteristics of cyclones in a climatological context, such as storm track density, intensity, and circulation patterns. For example, Pinto et al. (2005) studied northern hemisphere cyclone activity in a $40 \mathrm{yr}$ period based on NCEP-NCAR data. Della-Marta et al. (2009) combined ERA-40 re-analyses with extreme value statistics to determine the storm climatology for the eastern North Atlantic and Europe. Frank \& Majewski (2006) reconstructed extreme historic storm events from ERA-40 reanalyses using different models with a spatial resolution from 2.8 to $40 \mathrm{~km}$. Due to its low spatial resolution, however, re-analysis data cannot capture local-scale variations of the terrain that are important for deriving reliable wind fields.

The main purpose of our study is to present a statistical-dynamical downscaling method for the as- sessment of the local storm climate related to synopticscale winter storms on a $1 \mathrm{~km}$ grid and to provide wind speed maps for Germany for different return periods (Heneka et al. 2006). Due to the apparently stochastic behaviour of local wind gusts related to thunderstorms, convective events are not considered. For the climatological period from 1971 to 2000, the strongest winter storms in terms of wind speed and spatial extension were identified by use of station data. Large-scale wind fields obtained from the ERA-40 re-analysis of the selected storms were downscaled by using the numerical model KAMM (Karlsruhe Atmospheric Mesoscale Model). Wind gusts were estimated from mean wind speeds and empirical gust factors that depend on land use data. At each grid point, an extreme value distribution function according to Gumbel was fitted to the simulation data to obtain hazard curves and hazard maps, that is, wind speed as a function of the statistical return period.

The paper is structured as follows. Section 2 presents the different data sets that were used in the present study and discusses data quality checks. In Section 3, we shortly describe the mesoscale model and the quantification of gust wind speeds. Section 4 discusses the methods, including storm detection, statisticaldynamical downscaling of large-scale wind fields with the mesoscale model and hazard analysis by extreme value statistics. Storm climatology patterns for different return periods and hazard curves are examined and compared with observations in Section 5. A final discussion and some conclusions follow in Section 6.

\section{DATA SETS}

The long-term assessment of extreme wind speeds with high spatial resolution requires the use of 2 different data sets: (1) measurement data to identify historic severe storm events and to nudge the simulation results to the observations and (2) 3-dimensional reanalysis data to initialise the numerical model. For evaluation purposes, observation and model data of a regional climate model, initialised by ERA-40 reanalyses, were used.

In the following, winter periods from September to April were considered only, as the occurrence of synoptic-scale storm events over Germany is restricted to that season.

\subsection{Surface station data}

For the detection of independent storm events (see Section 4.1), the definition of the nudging field (see Section 4.2) and the evaluation of the model results 
(see Section 5.2), we used wind measurements from main meteorological watch offices and automatic weather stations of the German Weather Service (Deutscher Wetterdienst [DWD]). These data sets comprise hourly means and daily maximum gust speeds. A station was considered when it was in operation continuously over at least a period of 20 yr between 1971 and 2000. To ensure objective and independent evaluation of the results, the observations considered for the nudging technique (31 stations) were not used for the evaluation (126 stations). Only the storm selection approach relies on all observations available. The locations of the observation sites are shown in Fig. 1.

Wind measurements are very sensitive to changing environments, measurement height, relocation, or changes in instrumentation. These limitations cause more-or-less strong inhomogeneities in the long-term time series. This is a major constraint in the consistent detection of single storm events. Based on the annual mean wind speed and additional metadata containing station information, we identified and, if possible, cor-

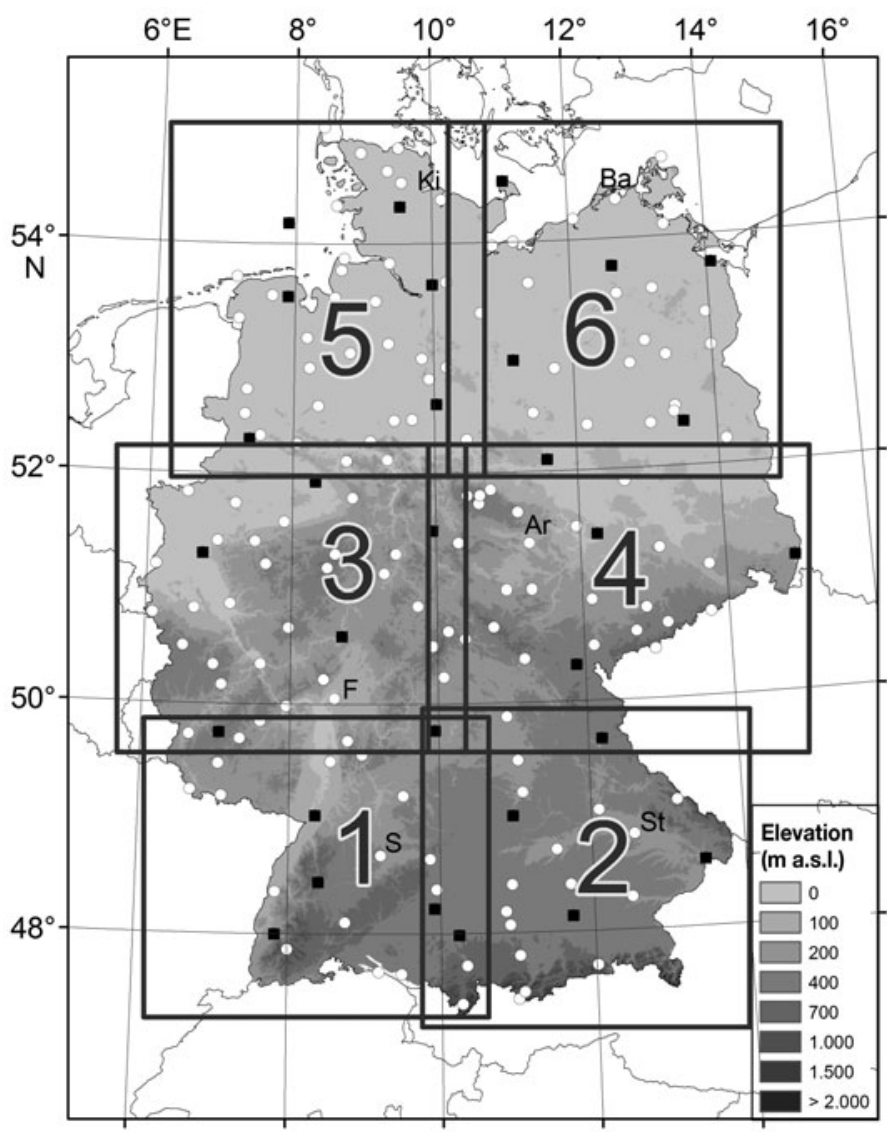

Fig. 1. Model topography with the 6 subdomains (S1 to S6) resolved by $1 \times 1 \mathrm{~km}$. Shading: orography height; white circles: locations of the surface stations used for evaluation; black squares: locations of the stations used for nudging. All stations were used for storm selection. Ki: Kiel; Ba: Barth; Ar: Artern; F: Frankfurt; S: Stuttgart; St: Straubing rected inhomogeneities in the time series. Stations with uncorrigible significant inhomogeneities were omitted from the present study.

Measurement errors, as well as local gusts related to thunderstorms, were detected and filtered out by comparing the daily maximum wind speed with both the hourly observations and time series from neighbouring stations. In case of doubt, weather charts of surface pressure and $850 \mathrm{hPa}$ geopotential height were considered in addition.

\subsection{ERA-40 re-analysis}

The ERA-40 re-analysis project of ECMWF supplies a comprehensive set of global analyses describing the atmospheric conditions for the time period from mid1957 to August 2002. The 3-dimensional variational technique applied involves comprehensive use of satellite data, including cloud motion winds from 1979. The meteorological data have a temporal and spatial resolution of $6 \mathrm{~h}$ and $2.5^{\circ} \times 2.5^{\circ}$, respectively. For more details, please consult the various reports of the ECMWF (e.g. Simmons \& Gibson 2000).

Re-analysis data used for the initialisation of KAMM are geopotential height, temperature, humidity and wind speed at 7 different pressure levels (1000, 925, $850,775,700,600$ and $500 \mathrm{hPa}$ ). The actual thermodynamic structure of the atmosphere cannot be resolved by using only a few pressure levels. This could be problematic when simulating severe downslope winds that may develop under stable stratified flow conditions (Smith 1985). Winter storms, on the other hand, cause almost neutral stratification, due to effective vertical mixing. In this case, a limited number of vertical layers is sufficient for the initialisation of KAMM.

\subsection{CLM-ERA40 re-analysis}

In addition, wind speed data from high-resolution simulations with the regional climate model (CLM; Rockel et al. 2008) for the same period were used. The intention was to reveal the principal characteristics and differences between the results as obtained by the presented simplified statistical-dynamical approach and a highly sophisticated numerical model that may capture the most important amplification mechanisms including dynamical instabilities.

The CLM is the climate version of the consortium for small-scale modelling (COSMO) model, which is the non-hydrostatic operational weather prediction model developed and applied by DWD. Gust wind speed is parameterised in terms of turbulent kinetic energy within the Prandtl layer. For more details on the model 
dynamics and physics consult the technical report of Steppeler et al. (2003). The simulations used in the present study were initialised by ERA-40 re-analysis and were multiply nested down to a resolution of approximately $7 \times 7 \mathrm{~km}$ (Feldmann et al. 2008). Hourly gust wind speed data are available for the whole period from 1971 to 2000. Since these model runs were performed with a special focus on the federal state of Baden-Württemberg, the domain covers only parts of Germany.

\section{MESOSCALE MODELLING}

\subsection{The KAMM model}

In order to reproduce reliable wind fields of historic storm events, the non-hydrostatic mesoscale model KAMM was applied to the re-analysis data. The KAMM model was used in several studies investigating the local wind field over complex terrain. It was applied for describing the regional wind climate of the upper Rhine valley (REKLIP 1995), simulating extreme wind speeds over the complex terrain of Southwest Germany (Kalthoff et al. 2003), or studying wind speedups over both idealised and complex terrain under storm conditions (Lux 2007). Special features of the model are the terrain-following coordinate system, the inelastic approximation of shallow convection for filtering sound waves and the interrelation to a basic state (Adrian 1987). Subgrid-scale fluxes are parameterised using a mixing length model with stability-dependent turbulent diffusion coefficients. The basic state is assumed to be hydrostatic and geostrophic. Further specifications can be found in Table 1.

In the present study, the model was confined to describing dry and stationary conditions. It was assumed that the modelled wind field represents the maximum mean velocities for a specific storm event. A horizontal grid spacing of $1 \times 1 \mathrm{~km}$, where most of the important structures of the wind field are assumed to be reproduced, was taken for all simulations. In a vertical direction, 35 layers with a decreasing distance to the surface were used; the lowest layer, where the wind fields are obtained, was set to $10 \mathrm{~m}$ above ground. No additionally nesting steps were performed to downscale the wind fields from ERA-40 to the final KAMM resolution.

Applying a multiple-nesting approach and considering a higher vertical layering in the KAMM model seems to be more reasonable. This, however, would substantially increase computing time, since highresolution modelling of extreme wind speeds requires extremely short time steps of around $1 \mathrm{~s}$ to meet the conditions of the Courant-Friedrichs-Levy (CFL) criterion. Downscaling the ERA-40 wind field for smaller areas such as the Subdomains S1 to S6, while keeping the boundary conditions constant, generates a rather homogeneous and smooth wind field at higher levels. Hence, the near-surface wind field is largely modified by orographic structures. Besides, applying the nudging technique every $2000 \mathrm{~s}$ has a damping effect on the generation of disturbances and waves. For all of these reasons it seems to be reasonable not to use a multiplenesting approach for downscaling wind fields of winter storms with the KAMM model.

Table 1. Overview of the features of the Karlsruher Atmospheric Mesoscale Model (KAMM)

\begin{tabular}{ll}
\hline Feature & Description \\
\hline Institution of origin & Institute for Meteorology and Climate Research, Karlsruhe Institute of Technology (KIT) \\
Equations & Non-hydrostatic, inelastic form to filter out sound waves \\
Scale & Mesoscale $\gamma$ and microscale $\alpha$ \\
Grid resolution & Vertical: 10 to $200 \mathrm{~m}_{\text {; }}$ horizontal: 0.1 to $10 \mathrm{~km}$ \\
Coordinate system & Terrain following coordinate system (eta) \\
Spatial discretisation & Arakawa A; finite differences \\
Advection & Flux-corrected-transport algorithm \\
Sub-grid scale turbulence & Mixing-length model; in case of stable thermal stratification the exchange coefficient by \\
parametrisation & Businger et al. (1971) is used ; in case of convective conditions, a non-closure of \\
& Degrazia (1989) is applied \\
Lateral boundary conditions & Scheme of Orlanski (1976) \\
Upper boundary conditions & Open boundary condition (Klemp \& Durran 1983) \\
Soil model & Prognostic, force-restore method \\
Vegetation model & 'Big leaf' concept \\
Radiation & Extinction-function (Pielke 1984) \\
Cloud parameterisation & No \\
Input data & Orography, soil and vegetation type, initial values for soil temperature and humidity; \\
& geostrophic wind, temperature and humidity \\
Initial state & Pre-processor for calculation of input data from large-scale models
\end{tabular}




\subsection{Gust wind speed}

Decisive for the impact of storms on vulnerable structures such as buildings or forest stands is the maximum wind speed that is related to short-term fluctuations during periods as short as a few seconds. These fluctuations, referred to as wind gusts, are the manifestation of atmospheric turbulence. Depending on the terrain's roughness and low-level stability, the wind gusts may exceed the mean wind speed (10 min average) by a factor of between 1.5 and $>2$. Mesoscale models, however, are not yet able to directly reproduce these short-term gusts. They only represent grid-scale wind speed with averaging times of between $10 \mathrm{~min}$ and $1 \mathrm{~h}$ (Panofsky \& Dutton 1994). This is due to a common deficiency in numerical models, where turbulence closure schemes are used to formulate the equations of motion. These shortcomings of numerical models usually lead to unrealistic gust speeds near the surface. Besides, internal dynamical structures of extratropical cyclones such as frontal systems with embedded convection, leading to cold air outflow and gust fronts, may locally enhance gust speeds. Convective structures with typical length scales of a few $100 \mathrm{~m}$ cannot be resolved and therefore cannot be reproduced by current operational weather prediction models. In a climatological perspective, however, the wind field over complex terrain is controlled especially by orographic properties rather than by more-or-less random convective gusts.

Therefore, 2 possible approaches exist for parameterising wind gusts from mean wind speeds. The physically based approach of Brasseur (2001) quantifies the shortterm fluctuations of the wind speed from turbulent kinetic energy and atmospheric stability in the planetary boundary layer. This method assumes that strong surface gusts originate from air parcels of higher levels that are deflected to the surface by turbulent eddies. In the other approach, wind gusts are determined by using constant empirical gust factors that are simply multiplied by the modelled mean wind speeds. Since Brasseur's method has not yet been fully tested, we used constant gust factors from literature that only depend on the land use at each grid point (Wieringa 1986). The gust factors listed in Table 2 were derived statistically from the ratio between turbulent fluctuations (averaged over a $3 \mathrm{~s}$ period) and mean wind speed (averaged over a $10 \mathrm{~min}$ period). This method is also proposed in design codes such as German building code (DIN 2005).

\section{METHODS}

\subsection{Investigation area}

Storm hazard was assessed for the whole area of Germany. The terrain features lowlands in the north,
Table 2. Gust factors used in the present study for different vegetation characteristics according to the studies of Wieringa (1986). The factors were determined by the ratio between gust and mean wind speed

\begin{tabular}{|lc|}
\hline Land use & Gust factor \\
\hline Water & 1.40 \\
Rock, sand, wetland & 1.45 \\
Grassland & 1.50 \\
Field & 1.50 \\
Deciduous forest & 1.65 \\
Mixed forest & 1.70 \\
Coniferous forest & 1.75 \\
Built-up area & 1.85 \\
\hline
\end{tabular}

some rolling terrain and low mountain ranges with a maximum elevation of $1493 \mathrm{~m}$ (Feldberg in the Black Forest) in the centre and south, and the Bavarian Alps with the Zugspitze as the highest peak (2962 m) in the very south (Fig. 1).

From various studies and reports (e.g. Kasperski 2002, Klawa \& Ulbrich 2003, Pinto et al. 2007) it is well known that frequency and intensity of winter storms in Germany decrease from the north to the south on the average. This is mainly due to the increasing distance from the North Atlantic, where strong extratropical cyclones usually originate. Storm-related wind fields typically exhibit a spatial extent on the order of $500 \mathrm{~km}$, which is smaller than the lateral extent of the total investigation area. Hence, a sample of historic storms for the whole area of Germany would violate the underlying statistics that require the consideration of the most extreme events for any subdomain (or any grid point). Besides, modelling of all 87 individual storm events in the period from 1971 to 2000 (see Appendix 1) for the whole domain would increase the need for computational capacities and costs by about a factor of 3 (total number of storms = 87 / sample size $=30$ ). Consequently, the total area was divided into 6 different subdomains, labelled S1 to S6 (see Fig. 1). In order to avoid sharp gradients in the final results between 2 subdomains, overlap areas with a distance of between 30 and $60 \mathrm{~km}$ are set in-between. In the overlap area, the wind speed is calculated from both subdomains by applying a linear distance weighting. Due to the asymmetric shape and the prevailing orographic structure of the total domain, both the size of the subdomains and the area of overlap between 2 subdomains differ slightly from one box to another. The methodology described in the following sections is applied to each of the 6 subdomains.

\subsection{Storm detection}

For each year from 1971 to 2000, the most intense storm events are identified (annual series). To consider 
not only the maximum wind speed at a specific site, but also the spatial extent of the wind field, a storm index, SI, is calculated for each day and for each subdomain, such that:

$$
\mathrm{SI}=\sum_{i} \frac{\mathrm{v}_{i}}{v_{\max \_i}}
$$

where $v_{i}$ is the daily maximum wind speed and $v_{\text {max } \_i}$ is the maximum wind speed recorded during a whole year at Station $i$. The storm with the highest SI within a year is selected for the sample. Summation over all $i$ stations available within a subdomain prevents locally enhanced gusts, which are not representative for a larger region, from entering the statistics. Normalising the recorded wind speeds in Eq. (1) instead of $v_{\max }$ by a specific percentile value, e.g. the 98th percentile (Pinto et al. 2007), does not really change the results (see Heneka et al. 2006 for the federal state of BadenWürttemberg).

The method of ranking all storms over the whole time period (partial series) as proposed, for example, by Coles (2001) is not applicable because in the subdomains S4 and S6 only a few stations are available that were continuously in operation from 1971 to 2000. The use of annual maxima, on the other hand, requires homogeneity only within a single year. Besides, by considering annual maxima, the storms can be regarded as statistically independent, which is a prerequisite for extreme value statistics. For example, the storms Vivian (26 February 1990) and Wiebke (1 March 1990), as well as the storms Lothar (26 December 1999) and Martin (28 December 1999) were triggered at the southern flank of the same central low and therefore cannot be treated as statistically independent. Atmospheric conditions that favour cyclogenesis may last for $>10 \mathrm{~d}$.

The storms selected for the statistics, in total 87 independent events, are listed in Table A1. To get an impression of the relevance of the single storms within each subdomain, we also added the year-toyear ranking. The ranking is based on a storm index that considers a $v_{\max }$ within the whole time period and not annually as in Eq. (1). Most of the storms affected only 1 (36 events) or 2 (23 events) subdomains. Only 4 storms stretched over 5 or 6 subdomains. A relationship between storm intensity in terms of their ranking and spatial extent could not be found. For example, Storm Lilli on 29 October 1996 affected 5 subdomains, but had a rather low intensity. Storm Daria on 25 January 1990, by contrast, affected just 1 subdomain, S3, but was the most severe event within $30 \mathrm{yr}$ in that area. Almost all storms featured wind directions between southwest and northwest (not shown).

\subsection{Modelling of selected storm events}

All 30 winter storms selected for each subdomain were modelled by a statistical-dynamical downscaling approach using the KAMM model. The steps towards obtaining a representative wind field shall be demonstrated for Storm Coranna on 11 November 1992 that mostly affected the central parts of Germany, Subdomain S3 (Fig. 2).

ERA-40 data at a time when wind speed reached its maximum were used as initial and boundary conditions of the relevant atmospheric variables. As the reanalyses strongly underestimate the wind speed near the ground, only data above the boundary layer were considered. Fig. 2a shows the $500 \mathrm{hPa}$ wind field from the ERA-40 data set on the $2.5^{\circ} \times 2.5^{\circ}$ grid for Europe. The centre of the extratropical depression was located in northern Germany, near the coast. The maximum sustained winds at 1200 UTC occurred in a broad belt that stretches from the southern coast of Ireland to the western part of Germany, with wind speeds of up to $40 \mathrm{~m} \mathrm{~s}^{-1}$.

For generating high-resolved initialisation fields, the ERA-40 data were projected onto the KAMM grid by an optimal interpolation routine. Since the basic state of KAMM has to be geostrophic and hydrostatic, both the geostrophic wind balance and the thermal wind relation were applied. In the planetary boundary layer, a standardised logarithmic wind profile was considered. The result is a $1 \times 1 \mathrm{~km}$ wind field that accounts for synoptic-scale disturbances only, but not yet for localscale orographically and roughness length-induced perturbations (Fig. 2b).

Using the interpolated 3-dimensional fields for geopotential height, temperature, moisture and wind, a first KAMM simulation was performed. Since the flow field is assumed to be stationary, the simulations were terminated after $4 \mathrm{~h}$ of computing time. By maintaining constant boundary conditions, as well as by applying the nudging approach every $2000 \mathrm{~s}$, the near-surface wind fields only vary marginally after that time. Extensive tests revealed that this setting time in the KAMM setup is sufficient for the completion of the swing-in phase and for reaching a nearly steady state. The modelled near-surface wind field, without any correction as shown in Fig. 2c, may be regarded as a superposition of the initial wind field pattern from the re-analyses and local-scale flow structures induced by topographic features. Even though the velocity of the initial wind field increases continually from northeast to southwest, the simulated wind speeds are highest in general over the mountain crests, whereas they are lowest over the flat terrain in the northwest.

The low temporal and spatial resolution of the ERA40 re-analyses may lead to significant differences 
(a)

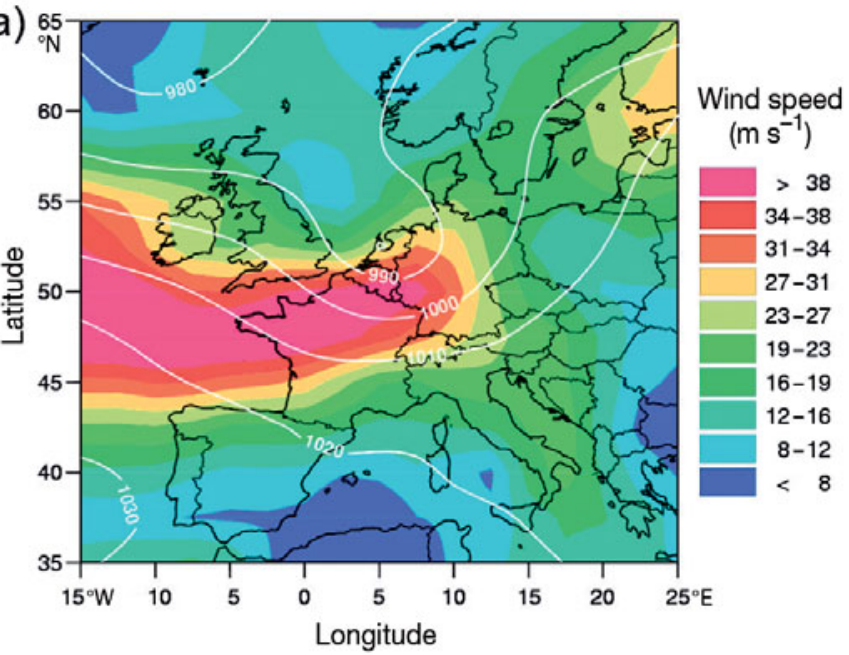

(c)

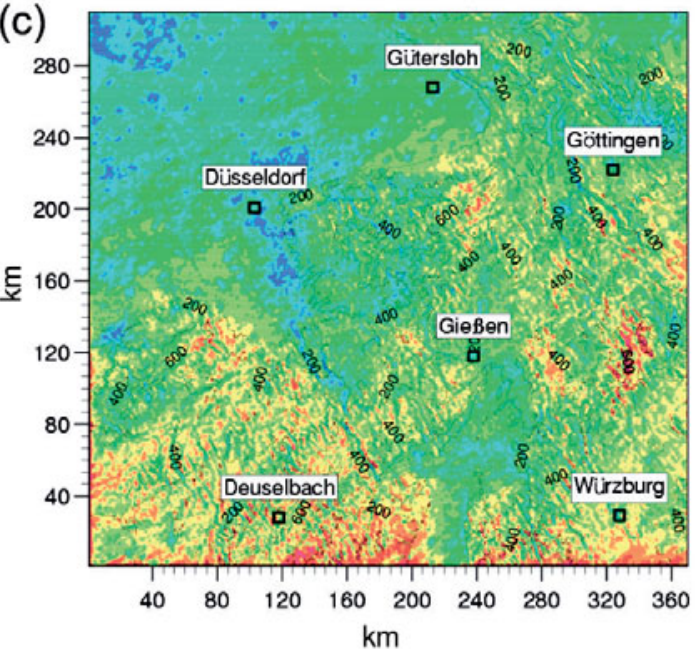

(e)

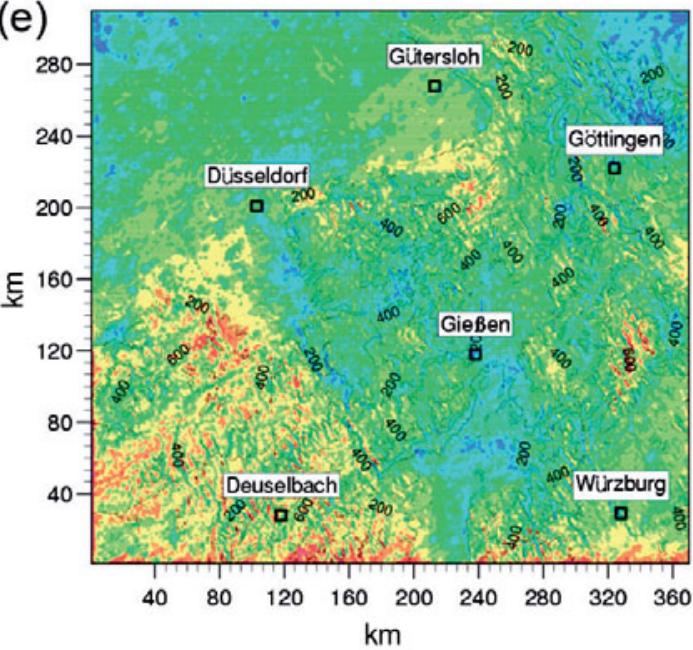

(b)

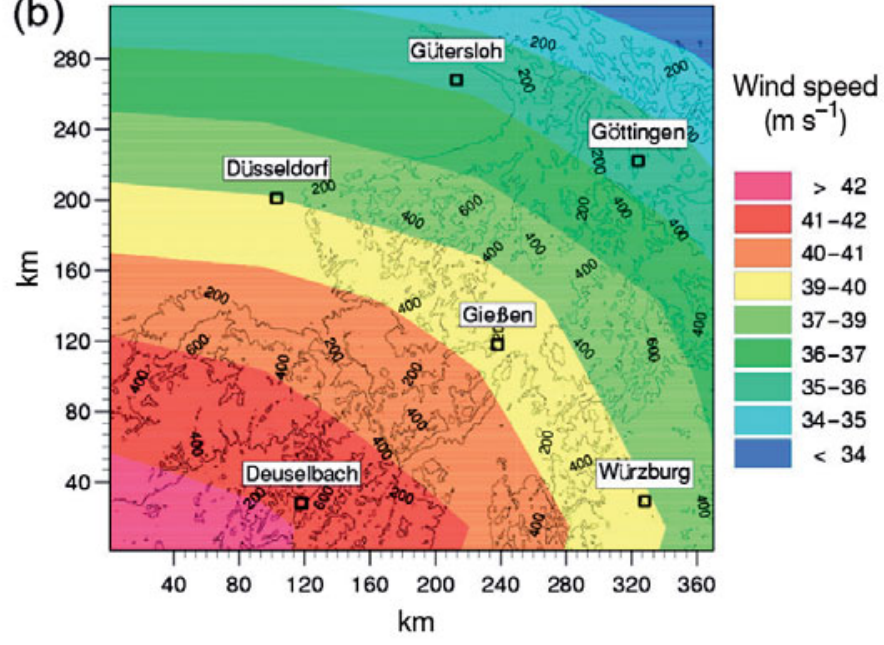

Wind speed
$\left(\mathrm{m} \mathrm{s}^{-1}\right)$

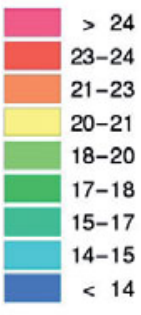

(d)

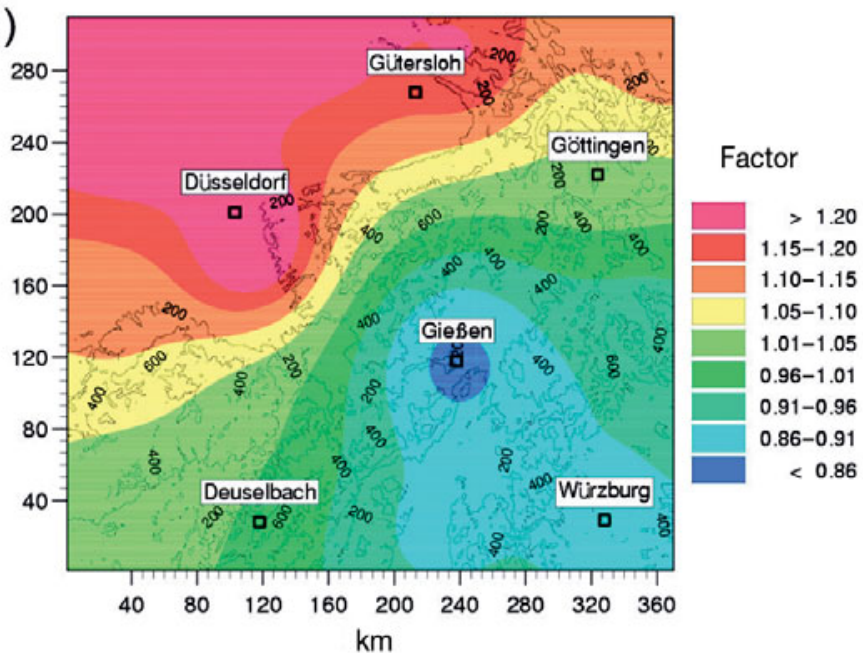

Fig. 2. Example of a model run for Storm Coranna on 11 November 1992: initialisation field from ERA-40 re-analysis data with (a) wind speed on the $500 \mathrm{hPa}$ level and surface pressure, (b) interpolated $500 \mathrm{hPa}$ wind field on the KAMM grid, (c) modelled nearsurface $(10 \mathrm{~m})$ wind field based on the interpolated ERA-40 data without correction, (d) interpolated ratio between modelled and observed wind speed, (e) near-surface $(10 \mathrm{~m})$ mean wind field as obtained from KAMM with respect to nudging and (f) nearsurface $(10 \mathrm{~m})$ gust wind field with consideration of gust factors. Note different keys in the panels 
between the observed and simulated wind fields with respect to both the magnitude and spatial patterns. To overcome these discrepancies, the wind field obtained from the first KAMM model run is adjusted to the observations by applying a nudging technique that is a weak relaxation towards an atmospheric reference state. The nudging term should be large enough to affect the solution, but small enough not to dominate over other terms. The nudging field is derived from observations of mean wind speed at 6 weather stations that are equally distributed and representative of the domain. The ratio between the modelled wind speed obtained from the nearest grid point around a station and the observed velocity is interpolated to the KAMM grid by applying a linear distance weighting. The nudging field for the final KAMM simulation is determined by multiplying these interpolated velocity factors by the initial wind field pattern from the reanalyses. This is shown in Fig. $2 d$, where the dimensionless factors vary between 0.8 and 1.2. In order to prevent the model from diverging too far from the basic state, the factors are generally limited to a range between 0.7 and 1.3. Furthermore, the nudging method is applied to the wind fields above the boundary layer only, where the nudging terms decrease linearly to unity on the upper model level.

Based on the initialisation data and the adjusted nudging field, a second KAMM simulation is performed, where the modelled wind velocities are forced to follow the observational data. This simulation (Fig. 2e) provides the mean wind field that is modified by local orography and adjusted to the observations. Compared to the first-guess model run (Fig. 2c), the wind speeds over the northwestern parts now are slightly higher, whereas they are somewhat lower over the southwestern parts. In general, the differences between the first and second simulations are in a range of $\pm 15 \%$.

As discussed in Section 3.2, the output of the mesoscale model is a mean wind speed similar to the $10 \mathrm{~min}$ mean. In order to obtain wind gusts, the modelled velocities at the grid points are multiplied by appropriate gust factors (see Table 2) that depend on the land use at the respective grid points. As expected, the final gust wind field (Fig. 2f) shows higher wind speeds in general, but also slightly different spatial patterns compared to the mean wind field. Especially over the hilly terrain in the southwest (Taunus), where coniferous forest (gust factor 1.75) predominates, the gust wind speeds are noticeably enhanced. Note that the domain comprising the final gust wind field is slightly reduced in order to prevent boundary effects of the model to enter into the statistics. These non-physical effects can be seen in the high gust speeds directly at the western and southern axes in Fig. 2c,e.

\subsection{Extreme value statistics}

Quantifying extremes of any physical parameter from a limited set of samples (observations or model data) requires the application of extreme value theory. Basically, 2 different methods exist for statistically describing the sample. One is the widely used peaksover-threshold (POT) method that considers all events over a defined threshold, which are modelled by the generalised Pareto distribution (Palutikof 1999). The other approach is the classical generalised extreme value (GEV) distribution, which comprises a family of 3 different probability distribution functions that consider only annual maxima (Fisher \& Tippett 1928). As already discussed in Section 4.2, we decided to apply the latter method to annual maximum gusts at each grid point, due to the lack of homogeneity in the observation data.

The cumulative distribution function $(\mathrm{CDF})$ of the GEV is defined as:

$$
\begin{aligned}
& F(x)=\exp \left[-\left(1-k \frac{x-\beta}{\alpha}\right)^{1 / k}\right] \text { for } k \neq 0 \\
& F(x)=\exp \left[-\exp \left(-\frac{x-\beta}{\alpha}\right)\right] \text { for } k=0
\end{aligned}
$$

where $k$ is the shape parameter that determines the type of extreme value distribution, $\beta$ is the mode that determines the location of the maximum, and $\alpha$ is the scale parameter affecting the extension in $x$-direction. The GEV distributions comprise the asymptotic distributions according to Fréchet and Weibull (Eq. 2a) and Gumbel (Eq. 2b), also known as Fisher-Tippett Types I, II and III extreme value distributions (Palutikof et al. 1999, Embrechts et al. 2003).

Extreme value statistics may be influenced by trends in the samples. Several studies have investigated the relation between frequency and intensity of cyclones or extreme winds in the past decades using either observation or re-analysis data. In summary, indications have been found — but no final proof — for a slight increase in cyclone activity in the past for some regions (e.g. Stein \& Hense 1994, Schmith et al. 1998, Bengtsson et al. 2006, Rockel \& Woth 2007). In our study, we performed trend analyses at several observation stations from means of the 3 most severe storms within a year under consideration of statistical independence (a time lag of $>3 \mathrm{~d}$ ). Even if some stations show a positive or negative trend, a general significant trend cannot be detected. In particular mountain stations such as Feldberg $(\mathrm{S} 1 ; 1490 \mathrm{~m})$, Hohenpeißenberg (S2; $977 \mathrm{~m})$, or Kahler Asten (S3; $839 \mathrm{~m}$ ), partly representing the conditions of the free atmosphere, do not show significant trends.

In the present study, extreme wind climatology was derived separately at each model grid point from the 
simulation results of the 30 most severe historic storm events in each subdomain. The method used to select the sample of representative storms (see Section 4.2) implies an independent and identically distributed (iid) population that is a basic prerequisite for the application of extreme value statistics. At most of the grid points, the Gumbel distribution $(k=0)$ fits the wind data best and was found to be the most robust compared to the other distributions of the GEV. For reasons of consistency, this distribution is applied in general, although the Weibull or Fréchet distribution may provide better results in a few cases. The inverse cumulative probability of Eq. (2b) is given by:

$$
v(p)=\beta-\alpha \ln [-\ln (1-p)]
$$

where $v(p)$ is the wind speed that is exceeded for a certain probability $p$ (or a statistical return period $T=p^{-1}$ ). The function $v(p)$ is called the hazard relation that defines the hazard curve. The unknown free parameters, $\mathrm{s}$ and $\beta$, are estimated by the method of probability weighted moments (PWM).

Any conclusion from the statistical analysis is subject to the uncertainties inherent in the distribution function, the method of determining the free parameters and in the extrapolation for low probabilities. Uncertainties in terms of confidence intervals are quantified using a bootstrap method as described by Efron \& Tibshirani (1993). This method is based on a number of re-samples that are obtained by random re-sampling with replacement from the original data set (nonparametric bootstrap). Confidence intervals on a $90 \%$ level (2-sided) for the probabilities (or return periods) are obtained from the bootstrap samples.

\section{RESULTS AND DISCUSSION}

\subsection{Climatology of extreme wind speeds}

Local extreme wind climatology is estimated in terms of statistically derived maximum gusts for specific exceedance probabilities. Based on the modelled wind fields, a statistical Gumbel distribution function according to Eq. (2b) or (3) is fitted to each of the approximately 400000 grid points for the whole domain. Examples of the plotting positions of the different events with appropriate hazard curves (Gumbel fits) are shown for a grid point located near Berlin (Fig. 3a) and for one in the upper Rhine valley (Fig. 3b). In both cases, the maximum gust speed of all individual storms more or less lie in a straight line that defines the Gumbel fit. All points are within the 2 -sided $90 \%$ confidence intervals. The most severe events at the 2 grid points (storms Niedersachsenorkan and Lothar) differ most from all other events of the sample. Although the method of PWM ap- plied to determine the free parameters, $\alpha$ and $\beta$ of the GEV (Eq. 3) does not strongly overemphasise the highest values, the estimated exceedance probabilities are sensitive to the most severe events. Hence, the results are also sensitive to the time period considered. For example, if the $30 \mathrm{yr}$ period considered for the statistics is shifted back just 2 yr (i.e. 1969 to 1998), then the strongest event at the grid in the Rhine valley (Fig. 3b), Storm Lothar in 1999, is not considered. This would yield a hazard curve with a different slope compared to that shown in the present figure.

Storm hazard maps obtained from the individual hazard curves at each grid point are shown in Fig. 4 for annual exceedance probabilities of $p=0.5$ and $p=$ 0.05 , corresponding to return periods of 2 and $20 \mathrm{yr}$, respectively. In the former case, the wind speed varies between 20 and $35 \mathrm{~m} \mathrm{~s}^{-1}$, whereas, in the latter case, it ranges from 26 to $45 \mathrm{~m} \mathrm{~s}^{-1}$. In general, the wind field is

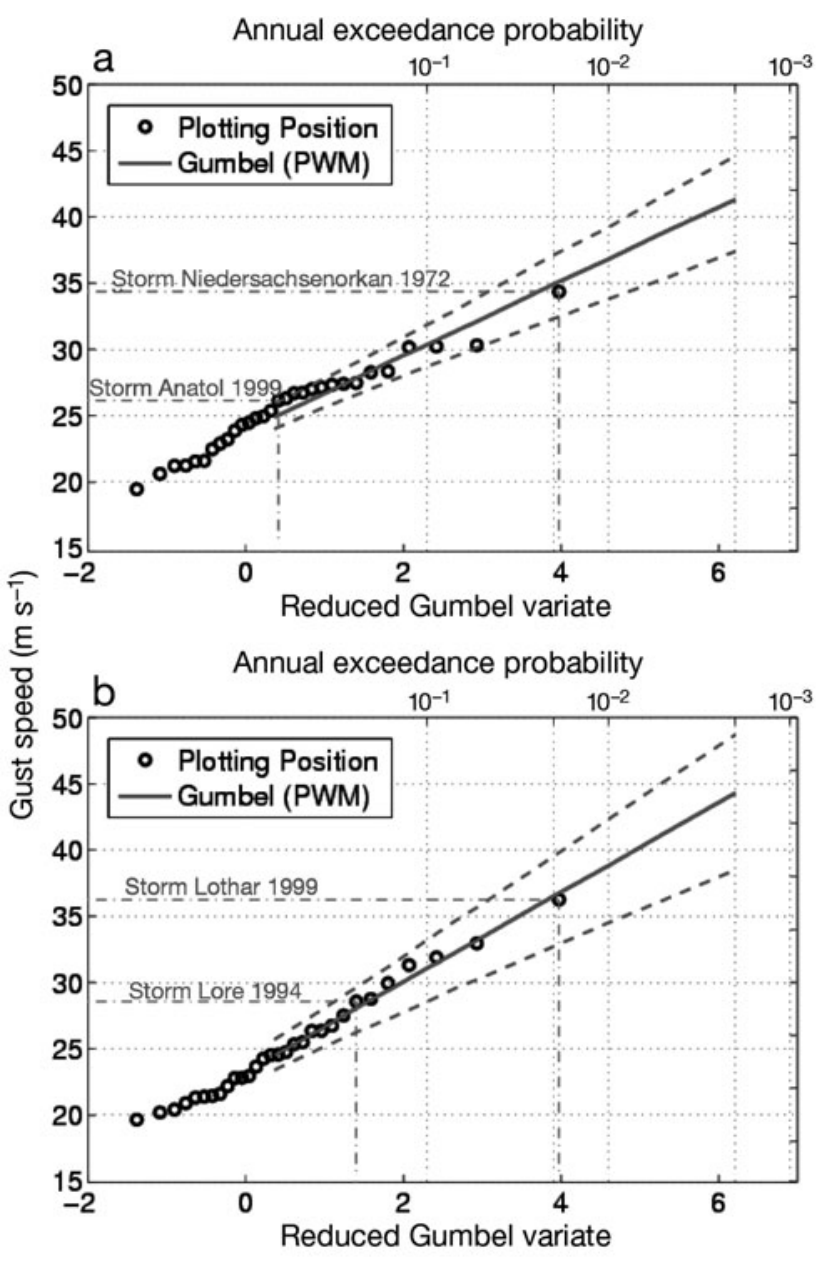

Fig. 3. Gust wind speed as a function of the exceedance probability, with $90 \%$ confidence intervals, for a location near (a) Berlin and (b) in the upper Rhine valley. Values are plotted for the storms Lothar (26 December 1999), Lore (28 January 1994), Niedersachsenorkan (13 November 1972) and Anatol

(3 December 1999) 


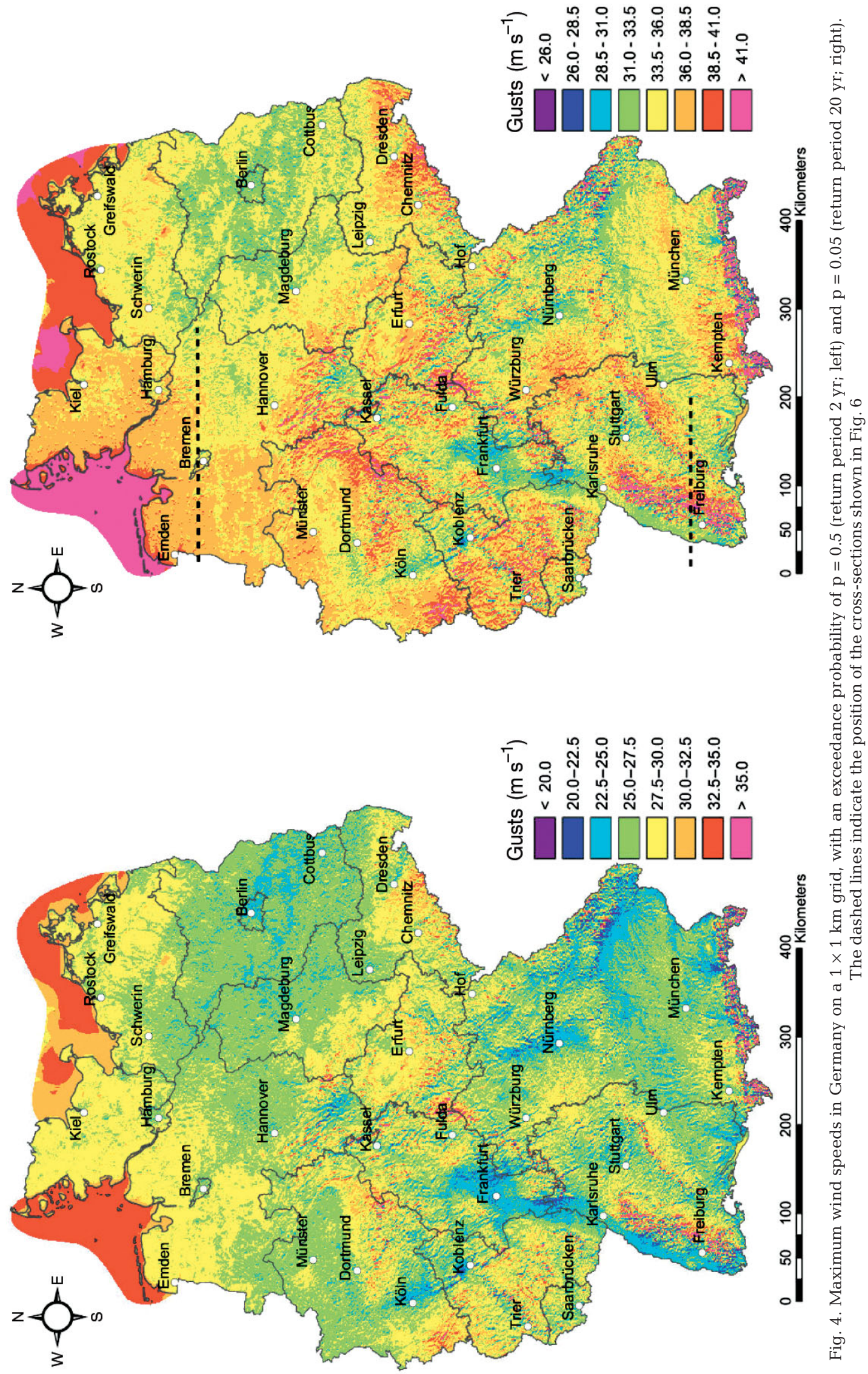


strongly determined by orographic features. Highest wind speeds appear near the top of the hills, as long as they are resolved by the model. In contrast to this, lowest values are typical for the valleys. The regions that are most affected by high wind speeds are the North Sea coast and the crests of the low mountain ranges or the Alps. Less affected are the regions of Brandenburg (eastern Germany), the Rhine-Main area (around Frankfurt), as well as the northern parts of Bavaria (southeastern Germany) and the southeastern parts of Baden-Württemberg (southwestern Germany). Over large built-up areas such as Berlin, Hamburg, or Munich, mean wind speeds are reduced by approximately $20 \%$, due to a greater roughness length compared to the surroundings. This effect is partly compensated by higher gust factors (see Table 2). Hence, the reduction in gust wind speed is only marginal (approximately $5 \%$ ) and, thus, hardly visible in the hazard maps of Fig. 4.

The wind fields reveal the superposition of atmospheric disturbances that are induced at several spatial scales. At the large scale, the variations of the climatological wind field result from the increasing number and intensity of extratropical cyclones in both south-to-north and east-to-west directions (e.g. Pinto et al. 2005, Della-Marta et al. 2009). Consequently, highest wind speeds occur over the northwestern areas ( 27.5 to $30 \mathrm{~m} \mathrm{~s}^{-1}$ for $\mathrm{p}=0.5$ ), whereas lowest speeds are found over the south and east of Germany (e.g. around Frankfurt and Berlin, with 22.5 and $25 \mathrm{~m} \mathrm{~s}^{-1}$, respectively, for $p=0.5$ ). The synoptically caused variations of the wind climatology are also reflected by the hazard curves at different grid points (Fig. 5). Selected for the

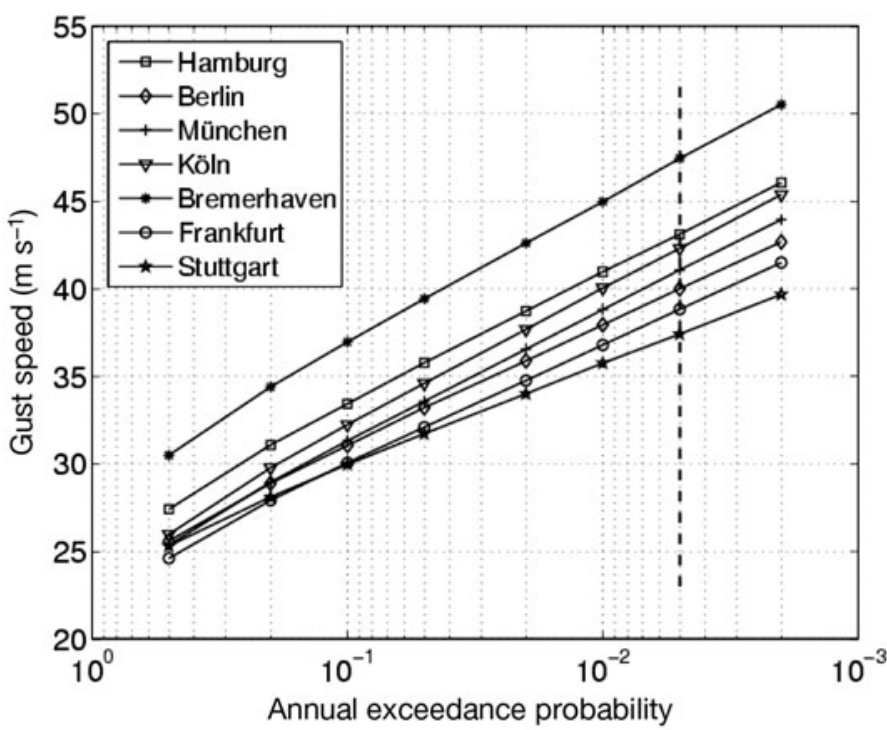

Fig. 5. Maximum gust speeds as a function of the exceedance probability for the locations of Hamburg, Berlin, Munich, Cologne, Bremerhaven, Frankfurt and Stuttgart comparison were locations over almost flat terrain with approximately the same roughness length. Irrespective of the probability, highest gusts are encountered at the northernmost stations of Bremerhaven and Hamburg. In contrast, the lowest values are obtained for the locations of Frankfurt and Stuttgart in the south. Most of the curves exhibit a similar slope. This means that the relative storm intensities and their statistical distributions are approximately the same. Only at Stuttgart and Berlin are the hazard curves flatter, because of a higher number of winter storms with lower velocities.

On a local scale, the near-surface wind field is modified mainly by the terrain's roughness and by orographic effects, in particular flow deflections at obstacles and enhanced vertical exchange of horizontal momentum. Over complex terrain, a distinct relationship between maximum gust wind speed and terrain height is obvious on a local and regional scale. At the $1 \mathrm{~km}$ resolution of the storm hazard maps, gust speed shows considerable small-scale variations that are more or less directly connected to local-scale terrain variations. Over the Black Forest mountains (Fig. 6a), for example, wind speed varies between 27 and $54 \mathrm{~m} \mathrm{~s}^{-1}$, that is, by a factor of 2 , at distances of a few kilometres. These small-scale variations relevant to the local storm climate diminish when spatially averaging the wind field. This can be seen especially over the Swabian Jura, where the gust speed averaged on a $20 \mathrm{~km}$ grid shows only marginal variability.

With increasing flatness of the terrain, the roughness due to the prevailing land use becomes more and more important and finally dominates over the orographic modifications of the flow. By way of example, Fig. 6b shows a decrease in gust speeds in a west-to-east direction despite the underlying complex orography with mountain tops $<120 \mathrm{~m}$. Both cross-sections confirm that high-resolution modelling is a prerequisite for the assessment of the local storm climate.

\subsection{Evaluation}

The present assessment of extreme wind climatology is subject to several uncertainties that are primarily due to the model representation of the storms and the low density of the observations. Hence, quantification of uncertainty is a key issue in order to estimate the reliability of the hazard estimation. In this section, the results will be evaluated by comparison with observation data from ground-based stations not used for computing the nudging fields. These comparisons are performed by hazard curves (Fig. 7) and scatter diagrams plotting the observed versus the simulated gust speeds (Fig. 8). Furthermore, the KAMM results are compared with results of CLM-ERA40 (Fig. 9). Due to the high 
spatial resolution of the hazard maps, the grid points nearest to the observation site were used without any interpolation. Wind speed observations are strongly modified by terrain and land use features in terms of roughness length, orography, or buildings in the direct vicinity of the site. Model data, on the other hand, are averages for a larger area of $1 \mathrm{~km}^{2}$ in size. Hence, any comparison is subject to the uncertainty of the different representations of terrain characteristics.

We selected 6 observation sites that represent the subdomains ( $\mathrm{S} 1$ to $\mathrm{S6}$; see Fig. 1) for the comparison of the hazard curves (Fig. 7). In general, the curves derived from observations and simulations are in good agreement. Especially the northernmost station, Kiel, as well as Frankfurt, both surrounded by almost flat terrain, feature an almost perfect reproduction of the hazard curves by the model approach, also for very low exceedance probabilities. Larger differences between both data sets occur for the stations of Barth (S6) and Stuttgart (S1), but for very low probabilities only. All figures show that the statistical uncertainty increases with decreasing exceedance probabilities. When con-

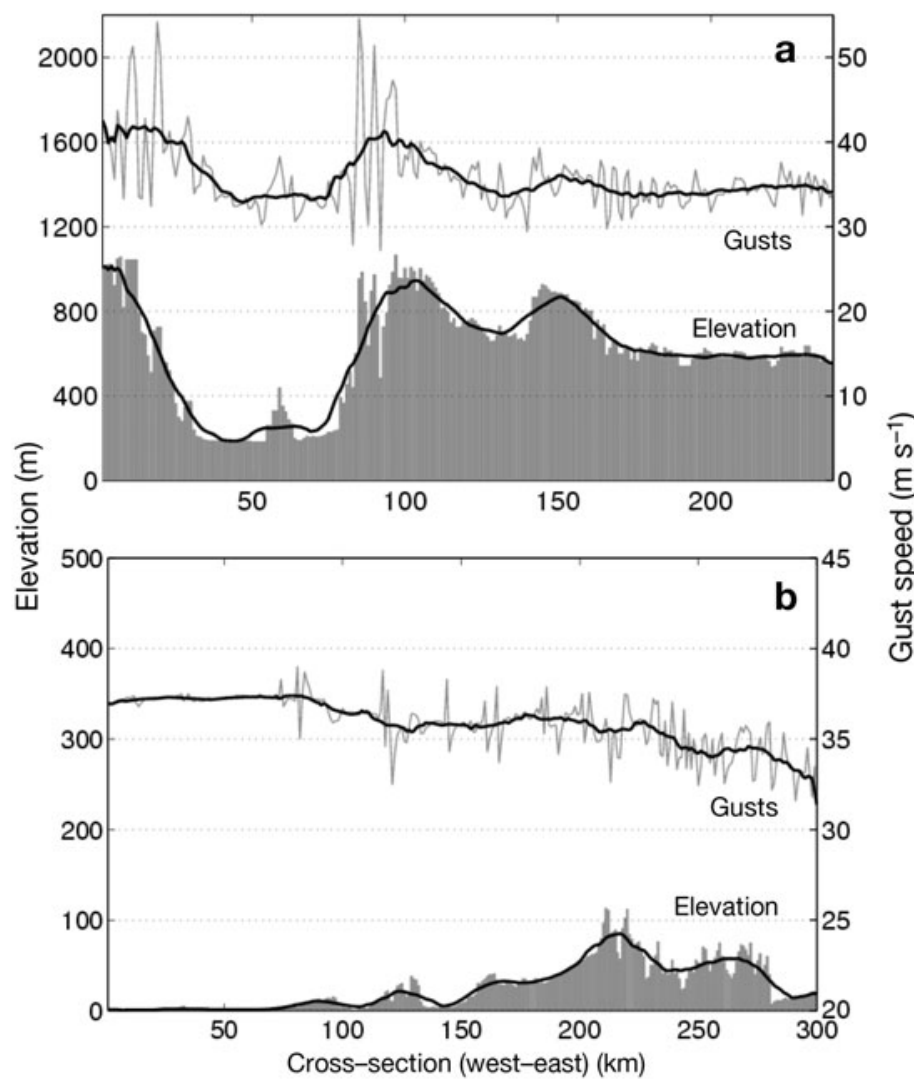

Fig. 6. Vertical cross-sections in west-east orientation through (a) the low mountain ranges of the Vosges, Black Forest and Swabian Jura and (b) some hilly terrain east of Bremen, with gust wind speed and orography on a $1 \mathrm{~km}$ grid and averaged over $20 \mathrm{~km}$ for an exceedance probability of $\mathrm{p}=0.05$ (see Fig. 4 for the locations of the cross-sections) sidering only return periods that are in the range of the investigation period without any extrapolation to higher levels (i.e. $\leq 30 \mathrm{yr}$ or $\mathrm{p} \geq 0.03$ ), the errors are $<10 \%$. Uncertainties of the hazard curves are lower for the model simulations compared to the observations, since the modelled wind fields exhibit a lower variability. Besides, observations at a single point do not ensure a perfect reproduction of the storm climate, either. In particular, measurement errors or station relocations, for example 3 times at the Stuttgart station within the time period considered, limit the direct application of observation data. It should be noted that the samples of extremes may vary between the simulations and observations. In the latter case, the strongest annual storms recorded at a particular observation site are considered, whereas the simulations take into account events that are highest for the whole subdomain only. Winter storms with a low spatial extension may enter the sample of observations, but not necessarily that of the simulations.

To check the robustness of the statistical-dynamical method, a total of 3657 samples were taken to compare the modelled against the measured gust wind speeds. Observations from 126 ground-based stations that are approximately evenly distributed over the investigation area were used (see Fig. 1). In order to reveal possible spatial differences on a large scale, the comparisons were performed separately for the 6 subdomains. Each station considered contributes a total of 30 different pairs with observed and modelled gust speeds. In the scatter diagrams presented in Fig. 8, each point marks the maximum gust wind speed of a selected storm (see Table A1) obtained at the measurement site and the nearest model grid point. As the number of stations within a subdomain is not constant, neither is the number of points in the scatter diagrams.

In general, the simulated and observed gust speeds are in good agreement, although there is large scatter as well. Vertical point accumulations in the scatter plot of S4 are due to a lack of data quality at some stations in the former German Democratic Republic. In all subdomains, the slope of the linear regression line determined by the method of least squares is between 0.47 and 0.78 . The axis intercept is also positive in all cases, with values ranging between 5.5 and $13.7 \mathrm{~m} \mathrm{~s}^{-1}$. Ideally, the slope should be near unity and the intercept near zero. A slope below unity in combination with a positive axis intercept means that the statistical-dynamical approach overestimates low wind speeds and underestimates high speeds. Discrepancies mainly result from the different representation of terrain features, as stated above, and from the initialisation method of the statistical-dynamical approach, where the wind field of ERA-40 data is assumed to represent the moment of highest wind speed. Another 

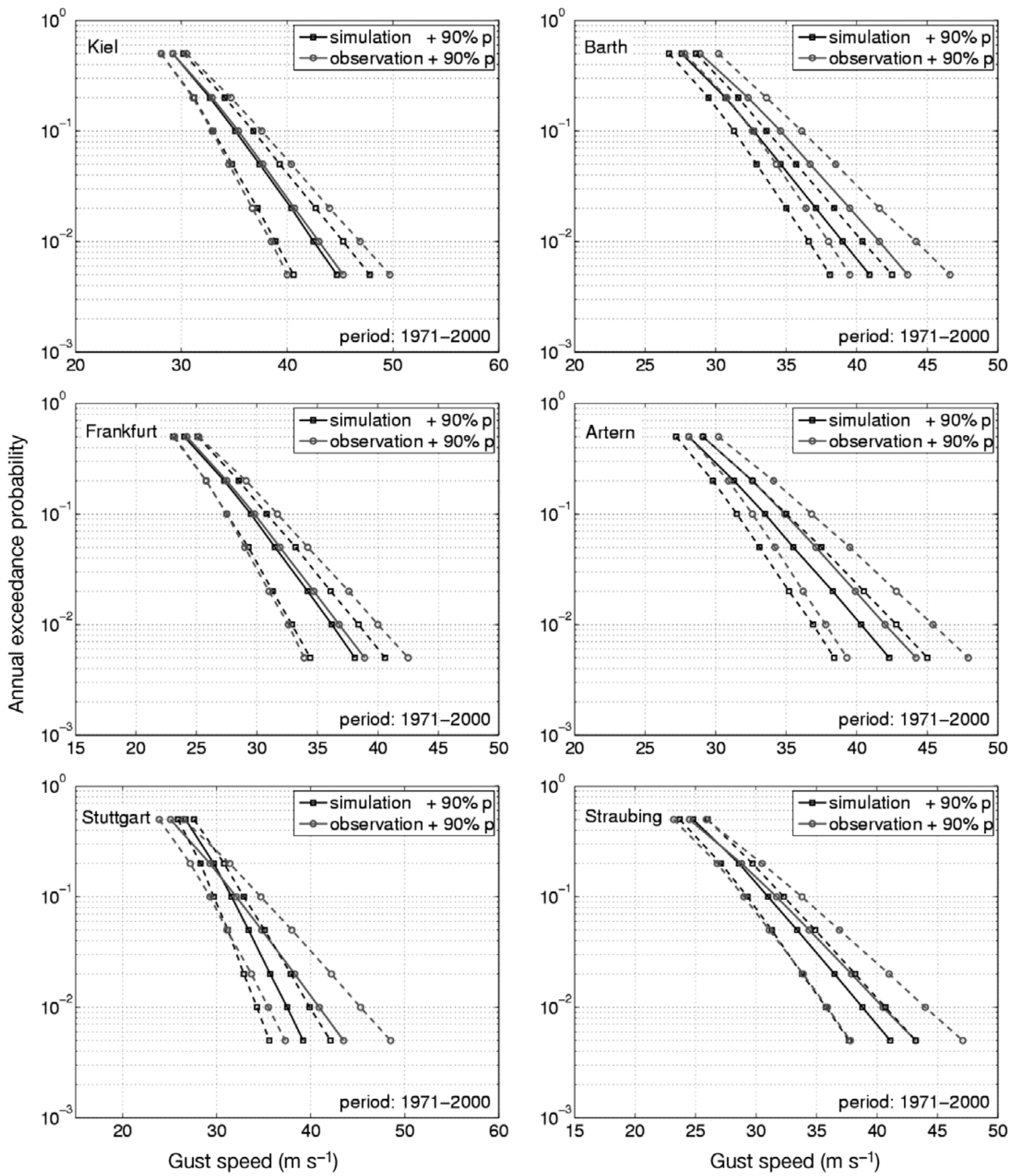

Fig. 7. Exceedance probabilities in the period 1971-2000 of gust wind speed for 6 different locations: Kiel (S5), Barth (S6), Frankfurt (S3), Artern (S4), Stuttgart (S1), and Straubing (S2). Locations are shown in Fig. 1. Solid lines with rectangles: simulations; solid lines with circles: observations of the nearest grid point; dashed lines: the 2 -sided $90 \%$ confidence intervals 

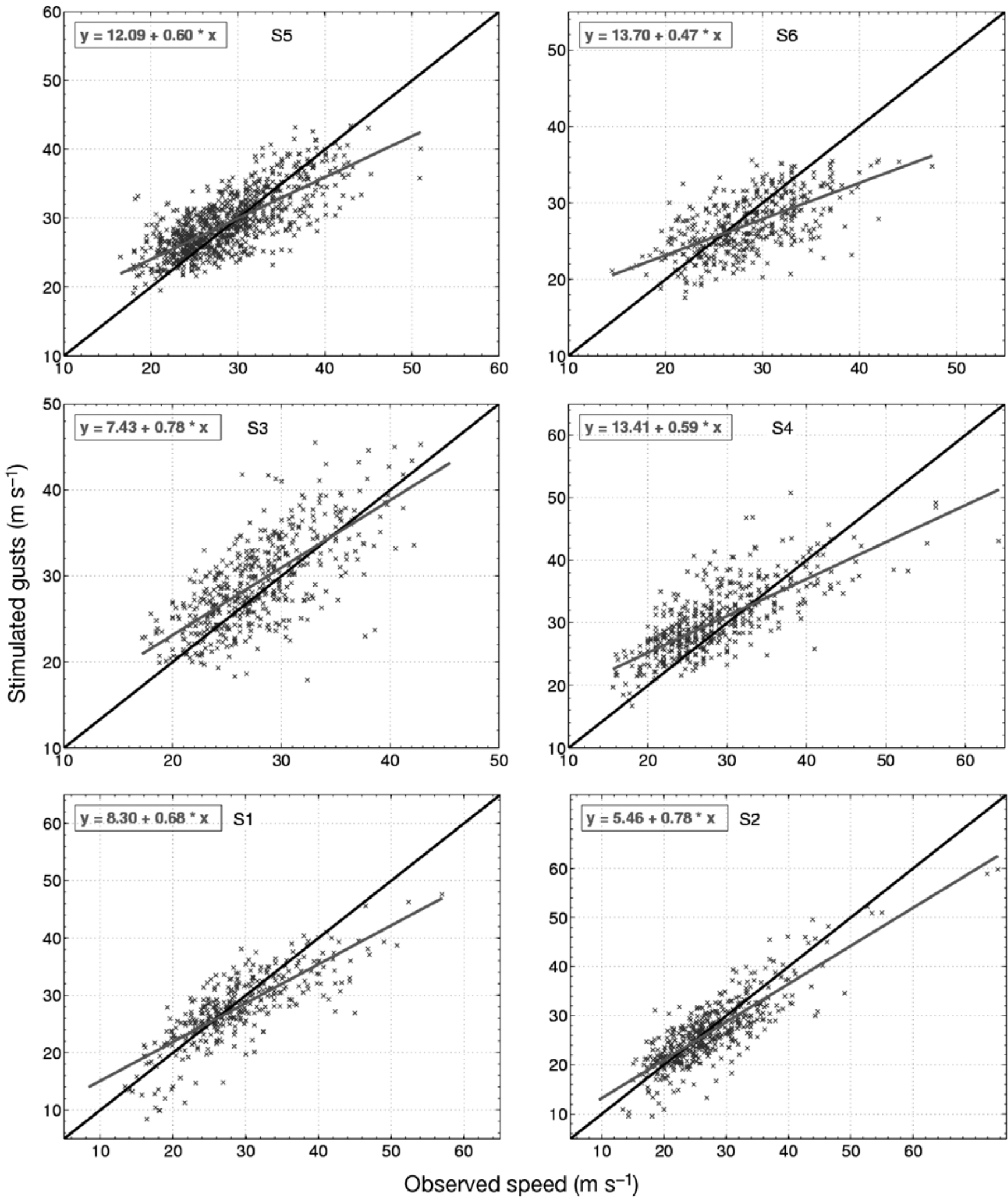

Fig. 8. Comparison of observed versus simulated gusts for all 6 subdomains from northwest (S5; top left) to southeast (S2; bottom right) based on the 30 selected storm events between 1971 and 2000. Observation sites are shown in Fig. 1 


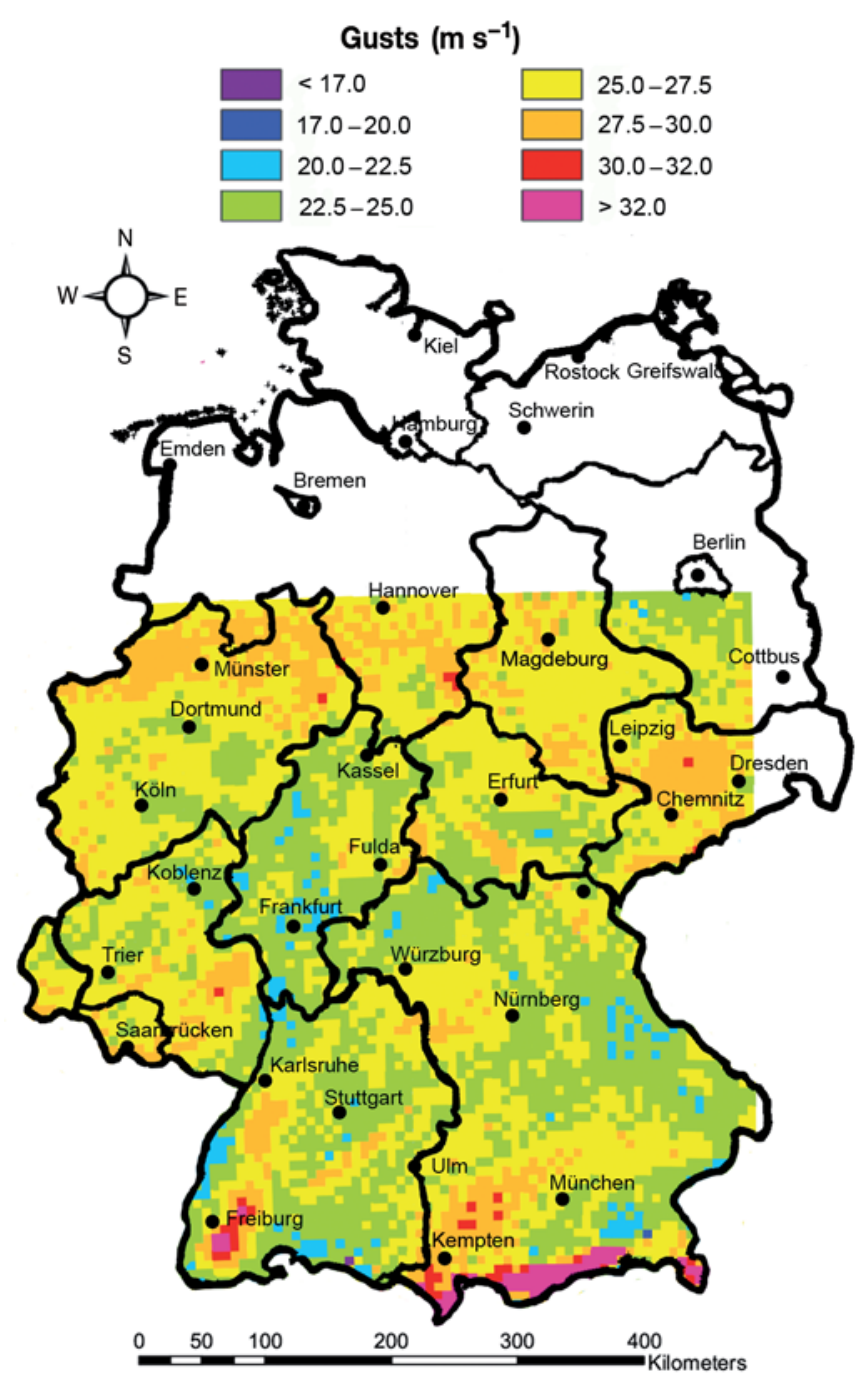

Fig. 9. Maximum wind speeds in Germany on a $7 \times 7 \mathrm{~km}$ grid with an exceedance probability of $\mathrm{p}=0.05$ (return period $20 \mathrm{yr}$ ), as obtained from CLM-ERA40 simulations

inaccuracy enters the model data when applying empirically derived gust factors that only depend on land use characteristics, and not on the stability of stratification and amount of wind speed. This becomes apparent when comparing the scatter diagrams for the different subdomains. The largest variance appears for the 2 northern domains, S5 and S6, where the terrain is almost flat and the near-surface wind field is dominated by the terrain's roughness associated with land use characteristics. For the 2 southern domains, S1 and S2, the wind field is determined primarily by orographic effects that predominate over those of the land use. Since these effects can be reproduced in high accuracy by high-resolution modelling, scattering is considerably reduced for regions with complex terrain.
Another potential weakness of the statisticaldynamical method may arise from the determination of steady-state maximum wind fields that do not account for any temporal evolution of the storms. Besides, the use of empirical gust factors seems to be a very rough approach to determine maximum gusts. Therefore, we applied the same extreme value statistics to simulations with the fully numerical model CLM that accounts for both effects (Fig. 9). In general, the spatial distribution of the CLM-ERA40 gusts is qualitatively similar to that of the KAMM model (see Fig. 4). Again, maximum gusts for a return period of $20 \mathrm{yr}$ occur over the highest low mountain ranges, even if the mountains are considerably lower at the resolution of $7 \mathrm{~km}$. Comparing the different model results quantitatively, it is obvious that the CLM-ERA40 runs significantly underestimate the magnitudes of the gusts by 10 to $50 \%$. In the southern Rhine valley, for example, the gusts are about $30 \%$ lower compared to the statistical-dynamical approach. The more to the south, the stronger the underestimation is. Since the KAMM model already underestimates strong wind speeds as discussed above, this means that the CLM-ERA40 model runs do not provide a better basis for the extreme value statistics.

From this evaluation, one may conclude that the statistical-dynamical method produces reliable results in terms of spatial distribution and magnitude of the gusts, despite its comparatively simple approach. This implies, that the model including the nudging technique considers the essential dynamics that are decisive for obtaining realistic wind fields.

\subsection{Return periods for Storm Lore on 28 January 1994}

From the hazard maps (Fig. 4) or hazard curves (Figs. $6 \& 7$ ), it is obvious that the gust wind speed for a specific return period or, conversely, the return period for a specific gust speed are local variables. Hence, estimation of a mean return period for a whole event is subject to the uncertainty resulting from the high spatial variability of the near-surface wind field, especially over complex terrain. In this section, spatially highly resolved return periods will be estimated exemplarily for the Storm Lore on 28 January 1994. Due to the large extent of the related wind field, this storm is 1 of 2 events that enter the samples of all 6 subdomains (see Table A1). This is the reason why we exemplarily selected Lore for discussion.

On that day, the southern flank of a deep extratropical cyclone with a central pressure $<970 \mathrm{hPa}$ located over Fennoscandia crossed the investigation area. The maximum measured wind speeds of the large-scale system were $>12$ on the Beaufort scale at many sites, 


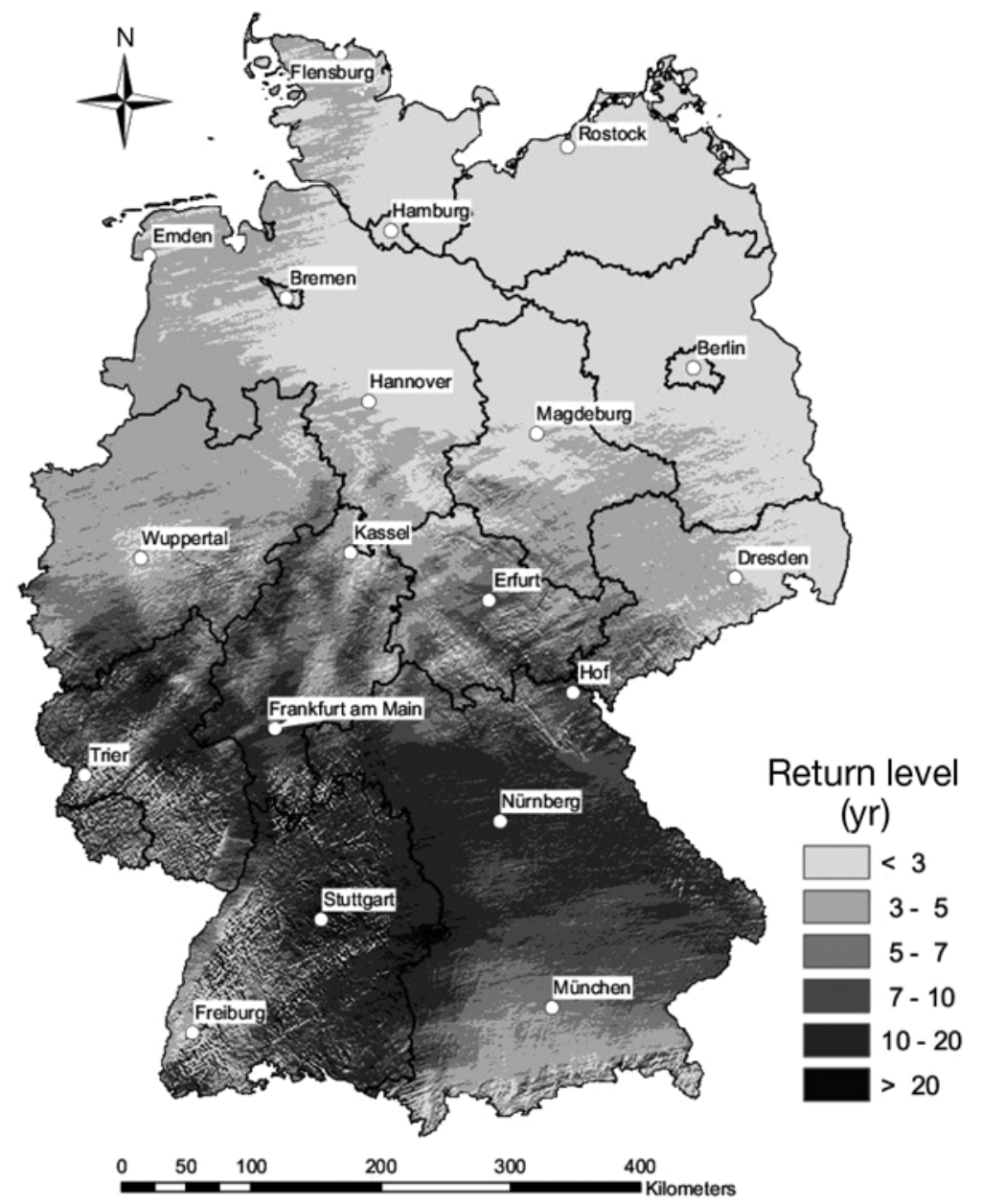

Fig. 10. Estimation of return periods for Storm Lore on 28 January 1994

\section{CONCLUSIONS}

We presented a new method for the assessment of extreme wind climatology with a very high spatial resolution of $1 \times 1 \mathrm{~km}$ and showed some applications to the whole area of Germany. The total domain was partitioned into 6 subdomains, for which a sample of the strongest annual storms between 1971 and 2000 was created. Spatially highly resolved wind fields were modelled by a statistical-dynamical approach that uses both ERA-40 re-analyses and observation data. Gust wind speeds were considered by empirical gust factors that solely depend on land use characteristics. Hazard curves for all grid points were determined from the modelled wind fields using a statistical Gumbel distribution function. The hazard maps revealed critical regions with potentially extreme wind speeds depending on exposure, terrain height and land use. Highest wind speeds were identified especially over the mountains, as well as near the coast and offshore. Comparisons between model data and observations confirmed the applicability and high skill of the method.

High-resolution modelling provides information about the gust wind speed for certain return periods, which is unique for a large area such as Germany. No comparable work has been conducted so far for this area. Despite some limitations, the method for the assessment of the high-resolution wind haz-

including several lowland stations (e.g. Saarbrücken $133 \mathrm{~km} \mathrm{~h}^{-1}$; List $131 \mathrm{~km} \mathrm{~h}^{-1}$ ). In the subdomains S1 and $\mathrm{S} 2$, it was the third most severe storm recorded within the 30 yr period.

From the modelled wind field, return periods were estimated for each grid point of the total domain based on the respective hazard curves. The resulting spatial distribution of the return periods is shown in Fig. 10. Highest periods of between 20 and $50 \mathrm{yr}$ can be found for some areas in the southern parts of Germany, whereas the lowest values $<5 \mathrm{yr}$ are given for the whole northern area. In contrast to the wind field, no relation between return periods and orography is found. This is because the enhancement of wind speed over the mountains is already considered in the storm climate as expressed by extreme value statistics (cf. Fig. 4). Even if the spatial variability of the return periods is significantly lower than the wind speed of the climatological wind fields, Fig. 10 illustrates the local character of the probabilities estimated. ard works very well. It is easily transferable to other regions, where the wind climate is dominated by extratropical storms.

On the other hand, the simplifications in applying the numerical model entail several inaccuracies and uncertainties. First, the wind field of a real storm is not stationary; rather, it may strengthen or weaken with time. This is indicated by the discrepancies of modelled versus observed wind speeds. A reliable reproduction of the non-stationary wind field requires the modelling of the temporal evolution of storm systems. To allow a large-scale extratropical storm to develop temporally, a very large model domain of $>1000 \mathrm{~km}$ in each direction is necessary. High-resolution modelling for such large domains, however, is associated with extremely high computational costs. Our study, on the other hand, aims at reproducing reliable extreme wind speeds over complex terrain in a climatological perspective, rather than reproducing exact wind patterns of single storms that occurred in the past. Furthermore, the initialisation method using ERA-40 re-analyses 
without a nesting step is a crucial point. Applying a multiple-nesting approach, however, would substantially increase computing time. The downscaling method for smaller areas with constant boundary conditions generates a rather homogeneous and smooth wind field at higher levels. Thus, the resulting nearsurface wind field is largely modified by local orographic structures. Therefore, it is reasonable not to consider a multiple-nesting approach for downscaling wind fields of winter storms with the KAMM model.

Another source of error in the model is the simplified estimation of gust wind speeds by empirical gust factors. In the future, it is planned to implement a method that considers atmospheric stability in terms of turbulent kinetic energy, as described in the study by Brasseur (2001). Finally, considering a higher number of observation data, especially over elevated terrain, would help improve the reliability of the wind field by the nudging technique. However, the data sets of several stations were inhomogeneous for the whole 30 yr period considered and had to be rejected. Of course, this requires a compromise between the demand for high data quality and a preferably high number of stations.

The wind field may be locally amplified by convective downdrafts or by flow accelerations due to crosswise circulations around frontal systems. These localscale amplification mechanisms cannot be reproduced by any numerical model in a 30 yr perspective, due to the low spatial and temporal resolution. Besides, they are not entirely and uniquely captured by the existing observation systems and cannot be reproduced by reanalysis data.

Despite several simplifications and limitations of the method, the results in terms of hazard curves that can be regarded as an average over the individual gust speeds show good agreement with the observations in general. Especially over mountainous terrain, where the synoptically caused wind speed is amplified by orographic influences, the results are of high quality. Consideration of both the temporal evolution of the storm systems and a more sophisticated parameterisation for the wind gusts does not necessarily ensure more reliable results, as was shown by the comparison between the present method and CLM-ERA40 data.

There are several applications that may rely on the local storm climate as provided by the hazard maps. Whereas the German building code gives gust wind speeds in a very coarse resolution that does not account for orographic or land use modifications of the flow, hazard curves and maps provided by our study can be used as an estimate of the local storm climate. Valuable information is supplied for construction purposes like the adaptation of buildings or structures to real wind loadings. In this way, the hazard maps can help prevent damage especially in regions that are highly exposed to storm hazard and risk. Insurance companies, in particular re-insurers, need accurate information about the frequency distribution of strong winds to quantify the insured wind risk. From historic storm events, probable maximum loss and risk curves may be derived in order to quantify the risk for a specific portfolio and to identify hot spots. Based on single events that are normalised by the storm climate in terms of wind speed for a certain return period, specific worst-case scenarios can be defined that help estimate the maximum possible loss. For risk assessment purposes, the hazard curves and maps can be combined with information about vulnerability from storm loss models for buildings or forest stands. This was done in the project 'Risk Map Germany' of the Centre for Disaster Management and Risk Reduction Technology, where the wind hazard maps were combined with a storm loss model (Heneka 2007) in order to quantify the storm risk for residential buildings in Germany.

In future work, it is planned to initialise the model with both real-time analysis and prognostic data. Together with the storm climate, as provided by the hazard maps, the potential hazard or return period can then be assessed immediately after or prior to an expected extreme storm event. By using an ensemble of regional climate model simulations, possible longterm trends in the intensity and/or probability of occurrence of winter storms not considered in this work could be evaluated for the same region.

Acknowledgements. We acknowledge the provision of wind data by the DWD and the provision of re-analysis data by the ECMWF. The authors are grateful to the 3 anonymous reviewers for their comments and suggestions that helped to improve the manuscript. This work was performed by the Centre for Disaster Management and Risk Reduction Technology (CEDIM), a joint venture of GeoForschungsZentrum Potsdam (GFZ) and Karlsruhe Institute of Technology (KIT).

\section{LITERATURE CITED}

Adrian G (1987) Determination of the basic state of a numerical mesoscale model from operational numerical weather forecasts. Contrib Atmos Phys 60:361-370

Adrian G, Fiedler F (1995) Simulation of unstationary wind and temperature fields over complex terrain. Contrib Atmos Phys 64:27-48

Belcher SE, Hunt JCR (1998) Turbulent flow over hills and waves. Annu Rev Fluid Mech 30:507-538

Bengtsson L, Hodges KI, Roeckner E (2006) Storm tracks and climate change. J Clim 19:3518-3543

Brasseur O (2001) Development and application of a physical approach to estimating wind gusts. Mon Weather Rev 129: $5-25$

Businger JA, Wyngaard JC, Izumi Y, Bradley EF (1971) Fluxprofile relationships in the atmospheric surface layer. J Atmos Sci 28:181-189 
Carruthers DJ, Hunt JCR (1990) Fluid mechanics of airflow over hills. In: Blumen W (ed) Atmospheric processes over complex terrain. Meteor Monogr 45, American Meteorological Society, Boston, MA, p 83-103

Coles S (2001) An introduction to statistical modelling of extreme values. Springer, London

Degrazia GA (1989) Anwendung von Ähnlichkeitsverfahren auf die turbulente Diffusion in der konvektiven und stabilen Grenzschicht. PhD dissertation, Wiss Ber Institut für Meteorologie und Klimaforschung 12, University of Karlsruhe (TH), Karlsruhe

Della-Marta PM, Mathis H, Frei C, Liniger MA, Kleinn J, Appenzeller C (2009) The return period of wind storms over Europe. Int J Climatol 29:437-459

DIN (2005) DIN 1055-4: Einwirkungen auf TragwerkeTeil 4: Windlasten. Deutsches Institut für Normung, Berlin

Dukes MDG, Palutikof JP (1995) Estimation of extreme wind speeds with very long return periods. J Appl Meteorol 34: 1950-1961

Efron B, Tibshirani R (1993) An introduction to the bootstrap. Chapman \& Hall, New York

Embrechts P, Mikosch T, Klüppelberg C (2003) Modelling extremal events: for insurance and finance. Springer, Berlin

Feldmann H, Früh B, Schädler G, Panitz HJ, Keuler K, Jacob D, Lorenz P (2008) Evaluation of the precipitation for south-western Germany from high resolution simulations with regional climate models. Meteorol Z 17:455-465

Fisher RA, Tippett LHC (1928) Limiting forms of the frequency distribution of the largest or smallest member of a sample. Proc Camb Philos Soc 24:180-190

Frank HP, Majewski D (2006) Hindcasts of historic storms with the DWD models GME, LMQ and LMK using ERA-40 reanalyses. Newsletter 109, ECMWF, Reading

Heneka P (2007) Schäden durch Winterstürme - das Schadensrisiko von Wohngebäuden in Baden-Württemberg. PhD dissertation, University of Karlsruhe (TH), Karlsruhe

Heneka P, Hofherr T, Ruck B, Kottmeier C (2006) Winter storm risk of residential structures - model development and application to the German state of Baden-Württemberg. Nat Hazards Earth Syst Sci 6:721-733

Kalnay E, Kanamitsu M, Kistler R, Collins W and others (1996) The NCEP/NCAR 40-year reanalysis project. Bull Am Meteorol Soc 77:437-471

Kalthoff N, Bischoff-Gauß I, Fiedler F (2003) Regional effects of large-scale extreme wind events over orographically structured terrain. Theor Appl Climatol 74:53-67

Kasperski M (2002) A new wind zone map of Germany. J Wind Eng Ind Aerodyn 90:1271-1287

Klawa M, Ulbrich U (2003) A model for the estimation of storm losses and the identification of severe winter storms in Germany. Nat Hazards Earth Syst Sci 3:725-732

Klemp JB, Durran DR (1983) An upper boundary condition permitting internal gravity wave radiation in numerical mesoscale models. Mon Weather Rev 111:430-444

Lux R (2007) Strömungsverstärkung von orographischen Grundstrukturen bei Sturmsituationen. PhD dissertation, Wiss Ber Institut für Meteorologie und Klimaforschung 40, University of Karlsruhe (TH), Karlsruhe
Meroney RN (1990) Fluid dynamics of flow over hills/mountains-insights obtained through physical modeling. In: Blumen W (ed) Atmospheric processes over complex terrain. Meteor Monogr 45, American Meteorological Society, Boston, MA

MunichRe (2007) Zwischen Hoch und Tief-Wetterrisiken in Mitteleuropa. Munich Re Publishing, Munich

Orlanski I (1976) A simple boundary condition for unbounded hyperbolic flows. J Comput Phys 21:251-269

Palutikof JP, Brabson BB, Lister DH, Adcock ST (1999) A review of methods to calculate extreme wind speeds. Meteorol Appl 6:119-132

Panofsky HA, Dutton JA (1994) Atmospheric turbulence: models and methods for engineering applications. John Wiley \& Sons, New York

Pielke RA (1984) Mesoscale meteorological modelling. Academic Press, New York, NY

Pinto JG, Spangehl T, Ulbrich U, Speth P (2005) Sensitivities of a cyclone detection and tracking algorithm: individual tracks and climatology. Meteorol Z 14:823-838

Pinto JG, Fröhlich EL, Leckebusch GC, Ulbrich U (2007) Changing European storm loss potentials under modified climate conditions according to ensemble simulations of the ECHAM5/MPI-OM1 GCM. Nat Hazards Earth Syst Sci 7:165-175

REKLIP (Regio-Klima-Projekt) (1995) Klimaatlas Oberrhein Mitte-Süd. Trinationale Arbeitsgemeinschaft REKLIP, vdf Hochschulverlag, Zürich

Rockel B, Woth K (2007) Extremes of near-surface wind speed over Europe and their future changes as estimated from an ensemble of RCM simulations. Clim Change 81: $267-280$

Rockel B, Will A, Hense A (2008) The regional climate model COSMO-CLM (CCLM). Meteor Z 17:347-348

Schmith T, Kaas E, Li T (1998) Northeast Atlantic winter storminess 1875-1995 reanalysed. Clim Dyn 14:529-536

Simmons AJ, Gibson JK (2000) The ERA-40 Project plan. Rep Ser 1, ECMWF, Reading

Smith RB (1979) The influence of mountains on the atmosphere. Adv Geophys 21:87-230

Smith RB (1985) On severe downslope winds. J Atmos Sci 42:2597-2603

Stein O, Hense A (1994) A reconstructed time series of the number of extreme low pressure events since 1880 . Meteorol Z 3:43-46

- Steppeler J, Doms G, Schättler U, Bitzer HW, Gassmann A, Damrath U, Gregoric G (2003) Meso-gamma scale forecasts using the nonhydrostatic model LM. Meteorol Atmos Phys 82:75-96

Whiteman CD, Doran JC (1993) The relationship between overlying synoptic-scale flows and winds within a valley. J Appl Meteorol 32:1669-1682

Wieringa J (1986) Roughness-dependent geographical interpolation of surface wind speed averages. Q J R Meteorol Soc 112:867-889

Wieringa J (1993) Representative roughness parameters for homogeneous terrain. Boundary-Layer Meteorol 63: $323-363$ 
Appendix 1. Storm events and their ranking in each subdomain (S1 to S6) (see Fig. 1 for locations)

\begin{tabular}{|c|c|c|c|c|c|c|c|c|}
\hline Year & Month & Day & $\mathrm{S} 1$ & $\mathrm{~S} 2$ & S3 & $\mathrm{S} 4$ & S5 & S6 \\
\hline \multirow[t]{3}{*}{1971} & 3 & 11 & - & - & - & 19 & - & 15 \\
\hline & 8 & 3 & - & - & 30 & - & - & - \\
\hline & 11 & $17 / 18$ & 27 & 26 & - & - & 30 & \\
\hline 1972 & 11 & 13 & 16 & 13 & 2 & 1 & 4 & 1 \\
\hline \multirow{4}{*}{1973} & 4 & 2 & 19 & - & 9 & - & - & - \\
\hline & 11 & 19 & - & - & - & - & 15 & - \\
\hline & 11 & 25 & - & - & - & 9 & - & 11 \\
\hline & 12 & 14 & - & 19 & - & - & - & - \\
\hline \multirow[t]{2}{*}{1974} & 1 & 17 & 11 & 14 & 11 & - & - & - \\
\hline & 12 & 29 & - & - & - & 10 & 17 & 17 \\
\hline \multirow[t]{3}{*}{1975} & 1 & 7 & - & 30 & - & - & - & - \\
\hline & 9 & 28 & - & - & - & - & 28 & - \\
\hline & 11 & 29 & 30 & - & 19 & 29 & & 25 \\
\hline \multirow[t]{2}{*}{1976} & 1 & 3 & - & 9 & 4 & 2 & 2 & 2 \\
\hline & 11 & 30 & 9 & - & - & - & - & - \\
\hline \multirow[t]{2}{*}{1977} & 11 & 15 & 7 & 10 & 16 & 16 & - & - \\
\hline & 12 & 24 & - & - & - & - & 8 & 8 \\
\hline \multirow[t]{4}{*}{1978} & 1 & 3 & - & 21 & - & 15 & 26 & - \\
\hline & 3 & 16 & - & - & 18 & - & - & - \\
\hline & 3 & 26 & - & - & - & - & - & 24 \\
\hline & 12 & 31 & 21 & - & - & - & - & - \\
\hline \multirow[t]{3}{*}{1979} & 11 & 8 & - & - & - & 25 & - & - \\
\hline & 12 & 11 & 15 & 17 & 22 & - & - & - \\
\hline & 12 & $17 / 18$ & - & - & - & - & 25 & 29 \\
\hline \multirow[t]{3}{*}{1980} & 2 & 4 & 23 & - & - & - & - & - \\
\hline & 4 & 2 & - & 27 & 24 & - & - & - \\
\hline & 4 & 19 & - & - & - & 22 & 19 & 13 \\
\hline \multirow{3}{*}{1981} & 1 & 3 & 13 & 16 & 17 & 26 & - & - \\
\hline & 2 & 3 & - & - & - & - & - & 20 \\
\hline & 11 & 24 & - & - & - & - & 11 & - \\
\hline \multirow[t]{3}{*}{1982} & 3 & 1 & - & - & 13 & - & - & - \\
\hline & 12 & 10 & 20 & - & - & - & - & - \\
\hline & 12 & 16 & - & 18 & - & 18 & 13 & 16 \\
\hline \multirow[t]{3}{*}{1983} & 1 & 18 & - & - & - & - & - & 10 \\
\hline & 2 & 1 & 10 & 12 & - & 13 & 6 & - \\
\hline & 11 & 27 & - & - & 10 & - & - & - \\
\hline \multirow[t]{3}{*}{1984} & 1 & $14 / 15$ & - & - & - & - & 5 & 6 \\
\hline & 11 & 23 & - & 4 & - & - & - & - \\
\hline & 11 & 24 & 5 & - & 3 & 3 & - & - \\
\hline \multirow[t]{3}{*}{1985} & 11 & $5 / 6$ & 28 & 29 & - & - & - & - \\
\hline & 11 & 10 & - & - & 27 & - & - & - \\
\hline & 12 & 6 & - & - & - & 23 & 12 & 14 \\
\hline \multirow[t]{4}{*}{1986} & 1 & 19 & - & 6 & - & - & 14 & - \\
\hline & 1 & 20 & - & - & - & 8 & - & 5 \\
\hline & 3 & 24 & 8 & - & - & - & - & - \\
\hline & 12 & 19 & - & - & 7 & - & - & - \\
\hline
\end{tabular}

Editorial responsibility: Peter Gleckler, Livermore, California, USA

\begin{tabular}{|c|c|c|c|c|c|c|c|c|}
\hline Year & Month & Day & $\mathrm{S} 1$ & $\mathrm{~S} 2$ & S3 & $\mathrm{S} 4$ & S5 & S6 \\
\hline \multirow{3}{*}{1987} & 1 & 2 & - & 23 & - & - & - & - \\
\hline & 3 & $27 / 28$ & - & - & 20 & - & 20 & 30 \\
\hline & 11 & 12 & 25 & - & - & 30 & - & - \\
\hline \multirow[t]{4}{*}{1988} & 2 & 6 & - & - & 23 & - & - & - \\
\hline & 3 & 25 & 14 & - & - & - & - & - \\
\hline & 12 & 19 & - & 20 & - & - & - & - \\
\hline & 12 & 24 & - & - & - & 27 & 27 & 22 \\
\hline \multirow[t]{4}{*}{1989} & 2 & 14 & - & - & - & - & 22 & - \\
\hline & 3 & $23 / 24$ & - & - & - & 28 & - & 28 \\
\hline & 12 & 13 & 22 & 22 & - & - & - & - \\
\hline & 12 & 17 & - & - & 25 & - & - & - \\
\hline \multirow[t]{3}{*}{1990} & 1 & 25 & - & - & 1 & - & - & - \\
\hline & 2 & 26 & - & - & - & 7 & 1 & 7 \\
\hline & 3 & 1 & 2 & 1 & - & - & - & - \\
\hline \multirow[t]{4}{*}{1991} & 1 & 6 & - & - & - & - & - & 23 \\
\hline & 1 & 9/10 & - & - & 26 & - & 18 & - \\
\hline & 12 & 18 & 24 & 25 & - & - & - & - \\
\hline & 12 & 23 & - & - & - & 21 & - & - \\
\hline \multirow{3}{*}{1992} & 3 & 13 & 18 & 11 & - & - & - & - \\
\hline & 11 & 11 & - & - & 8 & - & - & - \\
\hline & 11 & 26 & - & - & - & 12 & 10 & 3 \\
\hline \multirow{3}{*}{1993} & 1 & 13 & - & - & - & - & 3 & - \\
\hline & 1 & 24 & - & - & - & 4 & - & 4 \\
\hline & 12 & 9 & 4 & 5 & 6 & - & - & - \\
\hline 1994 & 1 & 28 & 3 & 3 & 5 & 5 & 9 & 18 \\
\hline \multirow[t]{2}{*}{1995} & 1 & $22 / 23$ & - & - & 12 & 14 & 16 & 12 \\
\hline & 1 & 26 & 6 & 7 & - & - & - & - \\
\hline \multirow[t]{2}{*}{1996} & 10 & 29 & 29 & 28 & 28 & 24 & - & 27 \\
\hline & 11 & 6 & - & - & - & - & 23 & - \\
\hline \multirow[t]{3}{*}{1997} & 2 & 13 & 12 & 8 & - & - & - & - \\
\hline & 2 & 25 & - & - & 14 & - & 21 & - \\
\hline & 3 & 28 & - & - & - & 6 & - & 19 \\
\hline \multirow[t]{3}{*}{1998} & 1 & 5 & - & - & - & - & 29 & - \\
\hline & 3 & 4 & - & - & 15 & 11 & - & 26 \\
\hline & 10 & 28 & 17 & 15 & - & - & - & - \\
\hline \multirow[t]{2}{*}{1999} & 12 & 3 & - & - & - & 17 & 7 & 9 \\
\hline & 12 & $25 / 26$ & 1 & 2 & 21 & - & - & - \\
\hline \multirow[t]{4}{*}{2000} & 1 & $29 / 30$ & 26 & 24 & - & - & - & 21 \\
\hline & 3 & 3 & - & - & - & 20 & - & - \\
\hline & 10 & 30 & - & - & 29 & - & - & - \\
\hline & 12 & 13 & - & - & - & - & 24 & - \\
\hline
\end{tabular}

Submitted: April 30, 2009; Accepted: January 5, 2010 Proofs received from author(s): March 9, 2010 